\title{
Magnitude scaling of short durations with closely spaced stimuli
}

JOHN A. MICHON INSTITUTE FOR PERCEPTION, SOESTERBERG, THE NETHERLANDS

A "fine grain" magnitude scale for duration is derived. It consists of two parts, each of which confirms the power law $\psi=a \phi b$. For intervals shorter than $500 \mathrm{msec}$ the characteristic exponent $b$ is approximately equal to 0.6 , for longer intervals $b \approx 1.1$. The latter result is in accord with earlier studies. The relation of this transition to similar effects obtained in indirect scaling experiments is discussed. The present results rule out the possibility that these effects are artificial byproducts of the motor response elicited by the indirect methods.

Short time intervals have been scaled by direct methods, fractionation and magnitude estimation, and the results generally conform to the power law

$$
\psi=\mathbf{a} \phi^{\mathbf{b}}
$$

in which $a$ is a scale factor and $b$ is the characteristic parameter, determining the relation between physical magnitude, $\phi$, and subjective magnitude, $\psi$ (Stevens, 1961; Stevens \& Galanter, 1957).

Characteristically, most authors have found that $1 \leq \mathrm{b} \leq 1.1$ (Chatterjea, 1964; Ekman \& Frankenhaeuser, 1957; Gregg, 1951; Mallick, 1962; Ross and Katchmar, 1951; Stevens \& Galanter, 1957).

The present experiment was carried out to check the author's suspicion that the earlier studies might have overlooked an anomaly in the magnitude scale at very short durations. The suspicion was based on the well known fact that Weber's law, $\Delta S=k S+a$, is particularly invalid for short durations (Fraisse, 1964; Michon, 1964, 1967), although some authors have ascribed the fact that relative sensitivity is passing through a maximum at approximately 600 msec to an uncontrolled effect of the motor system on the S's response (Treisman, 1963). In addition, the subjective quality of "duration" undergoes quite marked changes between $50 \mathrm{msec}$ and $3 \mathrm{sec}$, and especially so between 0.5 and $1 \mathrm{sec}$ (Fraisse, 1964). The motor artifact theory, admittedly, does not account for these phenomenological transitions. On the other hand, the absence of a simllar transition effect in magnitude estimation experiments appeared to be directly supporting it, since magnitude estimation requires a symbolic rather than a motor response.

There appeared to be another possibility, however, in the light of the customary density of stimulus durations in the critical range below 1 or 2 sec. In most investigations the interspace between stimuli has been $250 \mathrm{msec}$, or at least a comparable interval. Scaling experiments thus will lack the resolving power which is needed to bring out any significant deviation from the power law at the low end of the scale.

The present study was undertaken to scan the time dimension more carefully than has hitherto been done by using closely packed stimuli in the range below 2 sec.

Method

Ten Ss took part in the experiment. All had had some previous training in time evaluation experiments. Each $S$ served in 10 sessions lasting approximately $45 \mathrm{~min}$ each. These were preceded by one special training session. In the course of five sessions Ss were given 15 presentations of each of 20 stimulus intervals, of which they had to estimate the durations in hundredths of a second. Five Ss first had five sessions in which the stimulus range was 100-1000 msec in steps of $50 \mathrm{msec}$, and subsequently five sessions with stimuli ranging from 100 to $2000 \mathrm{msec}$ in steps of $100 \mathrm{msec}$. For the other five Ss this order was reversed. Depending on the stimulus range, a standard interval "100" (=1 sec) or "200" (=2 sec) was presented three times in succession after each block of five estimations. The 3000 odd stimuli of each of the two range conditions were presented in a pseudorandom order, which was different for every $\mathrm{S}$. The stimuli were square bursts of a $2000 \mathrm{cps}$ pure tone at a level of $45 \mathrm{~dB}$ above threshold, made audible to $\mathrm{S}$ through a headphone. Timing of the stimuli was accomplished by means of an electronic gate and a digital counter, which could be preset, in msec steps, to any value up to $9999 \mathrm{msec}$.

\section{Resulis}

The results have been summarized in Fig. 1. The data points represent the medians of the geometric means of the 15 estimates given by each $\mathrm{S}$. The vertical bars show the interquartile ranges of the interindividual data. The dots refer to the $100-1000 \mathrm{msec}$ range, the crosses to the $100-2000 \mathrm{msec}$ condition. The lines in Fig. 1 were fitted to the data by eye and hand.

\section{Discussion}

The magnitude scale for short intervals is clearly anomalous. While the upper part fully confirms the results of previous studies, the intervals shorter than 500 or $600 \mathrm{msec}$ follow a quite distinct rule, though it too obeys the power law. The estimated values of the exponent $b$ are 1.1 and 0.6 , respectively. Thus, in magnitude estimation a similar transition effect appears to be present as was found in differential threshold measurements. Consequently, the deviation 


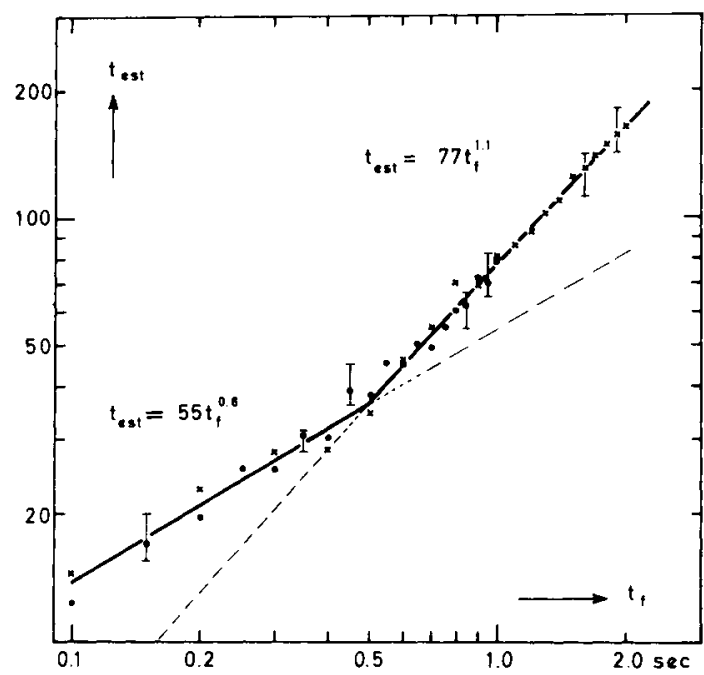

Fig. 1. Magnitude estimation scale for short durations.

from Weber's Law is unlikely to be an artifact caused by the motor system as a byproduct of the production techniques (Treisman, 1963). In the present experiment a symbolic (verbal) representation is required. Hence, the $\mathrm{S}$ may only use motor cues with which, in some unknown way, a cognitive representation has become associated. In that case the observed transition in sensitivity for duration should not be called an artifact; in the end, all perception of duration is based on cues, presumably of perceptual as well as of kinesthetic nature. Verbal estimation does, however, exclude the possibility of making direct use of motor cues such as pendular movements of hand, arm, or head, which cannot be ruled out in other scaling methods, such as production or reproduction.

A second conclusion that can be extracted from Fig. 1 is that both the exponents of the two parts of the scale and the point of transition at $500 \mathrm{msec}$ prove invariant under the two range conditions. If the transition were caused by a range or anchor effect (Helson, 1964), the results would have been quite different under the two conditions. Since this is not the case, it must be concluded that the shift in the slope of the lines in Fig. 1 represents a genuine characteristic of time perception. It can probably be equated to the point of maximum sensitivity and the "indifference interval," i.e., the point along the time scale at which neither under- nor overestimation of duration occurs. Moreover, this is the point where, subjectively, intervals change from "short" to "long," and where, according to Fraisse (1956), the perception of rhythm is superseded by the perception of duration.

No satisfactory unifying explanation has been offered for these phenomena thus far, although they were among the first to be discovered in the psychophysical analysis of time. However, beyond any reasonable doubt is the existence of an abrupt change in judgment process at $500-700 \mathrm{msec}$ that is due to the properties of time evaluation process, rather than to the peripheral conditions of the experimental situation.

References

CHATTERJEA, R. G. Temporal duration: ratio scale and category scale. J. exp. Psychol, 1964, 67, 412-416.

EKMAN, G., \& FRANKENHAEUSER, M. Subjective time scales. University of Stockholm, Psychol. Lab. Rep. No. 49, 1957.

FRAISSE, P. Les structures rythmiques, Louvain: Studia Psychologica, 1956.

FRAISSE, P. The psychology of time. London: Eyre and Spottiswoode, 1964.

GREGG, L. W. Fractionation of temporal intervals. J. exp. Psychol., 1951, 42, 307-312.

HELSON, H. Adaptation level theory. New York: Harper \& Row, 1964.

MALLICK, A. K. A scale for the measurement of subjective duration. J. exp. Psychol Res. (Madras), 1962, 6, 1-3.

MICHON, J. A. Studies on subjective duration: I. Differential sensitivity in the perception of repeated temporal intervals. Acta Psychol., 1964, $22,441-450$.

MICHON, J. A. Timing in temporal tracking. Soesterberg: Institute for Perception , 1967.

ROSS, S., \& KATCHMAR, L. The construction of a magnitude function for short time intervals. Amer. J. Psychol, 1951, 64, 397-401.

STEVENS, S. S. The psychophysics of sensory function. In W. A. Rosenblith (Ed.), Sensory communication. New York: MIT/Wiley, 1961. Pp. 1-33.

STEVENS, S. S., \& GALANTER, E. H. Ratio scales and category scales for a dozen perceptual continua. J. exp. Psychol, 1957, 54, 377-411.

TREISMAN, M. Temporal discrimination and the indifference interval: Implications for a model of the internal clock. Psychol. Monogr., 1963, 77 (Whole No. 576). 